\title{
Google, Online Search and Consumer Confusion in Australia ${ }^{1}$
}

\author{
Amanda Scardamaglia ${ }^{2}$ and Angela Daly ${ }^{3}$ \\ PRE-PRINT VERSION OF ARTICLE FORTHCOMING IN THE INTERNATIONAL \\ JOURNAL OF LAW AND INFORMATION TECHNOLOGY (2016)
}

\begin{abstract}
The legality of the operation of Google's search engine, and its liability as an Internet intermediary, has been tested in various jurisdictions on various grounds. In Australia, there was an ultimately unsuccessful case against Google under the Australian Consumer Law relating to how it presents results from its search engine. Despite this failed claim, several complex issues were not adequately addressed in the case including whether Google sufficiently distinguishes between the different parts of its search results page, so as not to mislead or deceive consumers. This article seeks to address this question of consumer confusion by drawing on empirical survey evidence of Australian consumers' understanding of Google's search results layout. This evidence, the first of its kind in Australia, indicates some level of consumer confusion. The implications for future legal proceedings in against Google in Australia and in other jurisdictions are discussed.
\end{abstract}

\section{Keywords:}

Consumer confusion; Google; intermediary liability; empirical evidence; trade marks; cyberlaw

\footnotetext{
${ }^{1}$ The authors would like to thank Dr Rachel Batty and Cheng Vuong for their research assistance and the participants at the Melbourne Law School Empirical Studies in Trade Marks Junior Scholars Forum (December 2014) and Scott Ewing for their thoughtful comments. Thanks also to David Bednall, Civilai Leckie and Vicki Huang for their time and assistance in the survey design process. This research was supported by grants from Swinburne Faculty of Business \& Law and Swinburne Faculty of Health, Arts and Design.

${ }^{2}$ Deputy Department Chair and Senior Lecturer, Swinburne Law School, Swinburne University of Technology (Australia)

${ }^{3}$ Vice Chancellor's Research Fellow, Queensland University of Technology (Australia); Adjunct Research Fellow, Swinburne Institute for Social Research; Research Associate, Tilburg Institute for Law, Technology and Society (Netherlands).
} 


\section{Introduction}

This article provides an empirically based assessment of Australian consumers' understanding of Google's search results layout, including the origin and provenance of the different kinds of results Google produces. This inquiry is undertaken in the wake of the Australian Google v ACCC litigation, when the judge at first instance, Nicholas J, considered that Australian internet users understood the difference between organic search results and Sponsored Links (now known as 'ads') and thus were not illegally mislead or deceived. However, no evidence of actual Australian consumer behaviour was adduced. Evidence of consumer understanding of Google's search results from other jurisdictions, especially in the context of trade mark and competition litigation, is inconclusive on this point.

Thus, this article and the empirical evidence presented here seek to understand: the extent to which actual Australian consumers understand the results produced by Google's search engine; to what extent, if any, they experience confusion in understanding the results; and what legal implications may flow from any misunderstanding or confusion identified.

First, the legal context is presented in Section 2. Legal proceedings in which empirical evidence of consumer understanding of Google's search results has been produced are identified and discussed. The legal challenge that Google has faced from a consumer protection perspective, and in particular, the High Court of Australia ('High Court') decision in Google Inc v Australian Competition and Consumer Commission ('ACCC') (2013) 249 CLR 435 is considered in detail.

Second, the empirical evidence of consumer understanding is presented in Section 3. The purpose of this research is to indicate the accuracy of Nicholas J's comments in Google v $A C C C$ regarding Australian consumers' understanding of the Google search results page. The 
survey questions tested participants' ability to identify and distinguish between paid-for advertising, organic search results and results from Google's affiliated services such as Google News. Participants' knowledge of the provenance of these different kinds of results whether paid-for advertising, generated by Google's search algorithm or coming from other services owned and operated by Google - was also tested.

The key findings of this empirical research indicate that Australian consumers lack understanding about the operation and origin of the different elements of the Google search results page. They are best able to understand and identify ads, as compared to their understanding and identification of organic results and results from subsidiary services. There is particular confusion in relation to the operation and origin of Google's Shopping service.

These findings cast doubt on Nicholas J's comments about Australian internet users in Google v ACCC, and may indicate a level of consumer confusion actionable at law. In light of the international trade mark litigation largely being decided in Google's favour, and the European competition investigation's status as ongoing yet resting on a questionable legal basis, it is submitted that an action in misleading and deceptive conduct, accompanied by appropriate supporting evidence, is the head of law most likely to succeed against Google as regards the legality of its search results page layout.

\section{Legal Context}

The Google Inc v ACCC decision at the heart of this article is one of a series of cases internationally examining the legality of Google's search engine on various grounds. Google has been met with allegations of copyright infringement, including in relation to its reproduction of images on its Google Image Service. ${ }^{4}$ Google has also been the subject of

\footnotetext{
${ }^{4}$ See, eg, Perfect 10 Inc v Amazon.com Inc, 508 F 3d 1146 (9th Cir, 2007). See also the German case Judgment of 29 April 2010: Bundesgerichtshof [German Federal Court of Justice], I ZR 69/08, 29 April 2010. Here, the
} 
defamation proceedings. ${ }^{5}$ Furthermore, it has been central to the debates around the right to privacy $^{6}$ and the 'right to be forgotten'. ${ }^{7}$ Additionally, Google has been the subject of two major competition investigations on both sides of the Atlantic and has been embroiled in a worldwide keyword advertising trade mark battle.

It is these latter actions which are of relevance to the discussion in this article since they have implicated internet users' understanding of Google's search results page layout, and empirical evidence of this understanding has been produced in the course of these competition investigations and trade mark infringement proceedings. The empirical part of this article asks whether consumers understand the layout of Google search results from a consumer protection perspective. As such, the nature and substance of both of these legal challenges will be discussed since they do indicate a lack of consumer clarity around Google search with this lack of clarity also being central to the challenge to Google's conduct pursuant to the Australian laws relating to misleading and deceptive conduct. However, in trade mark law, actions against Google have been unsuccessful, while competition investigations have proved legally problematic, as will be explained in more detail below. While the ACCC was also unsuccessful in its action against Google for misleading and deceptive conduct, this was due to the facts of the case rather than any deficiency in the law, so the possibility remains open for future litigation under this head of law, as will be explained.

Court decided that by showing image thumbnails of an artist's original works, Google was not in breach of copyright because the artist had not used the technical measure allowing her to stop Google from indexing her site. Although the artist had not explicitly consented to the use of the images, she had not blocked her website from being indexed by search engines thus giving implicit permission to any search engine to display the thumbnail images.

${ }^{5}$ On this point, the Trkulja v Google Inc LLC (No 5) [2012] VSC 533 (12 November 2012) case is relevant. Here, the Supreme Court of Victoria found Google liable as the publisher of defamatory material as published in its organic search results.

${ }^{6}$ Mosley v Google [2015] EWHC 59 (QB) (15 January 2015).

${ }^{7}$ Case C-131/12 Google Spain SL, Google Inc v Agencia Española de Protección de Datos, Mario Costeja González (ECR, 13 May 2014). In this case, the Court of Justice of the EU ruled that under European data protection law, individuals in certain circumstances can ask Google to stop listing certain links to information about them in its search results page. See: David Lindsay, 'The 'Right to be Forgotten' by Search Engines Under Data Privacy Law: A Legal Analysis of the Costeja Ruling' (2014) 6 Journal of Media Law 159; Orla Lynskey, 'Control over Personal Data in a Digital Age: Google Spain v AEPD and Mario Costeja Gonzalez' (2015) 78 Modern Law Review 522. 


\subsection{Competition Investigations}

Google has been the subject of claims of anticompetitive conduct in both Europe and the United States (US) in relation to the layout of its search results page. ${ }^{8}$ At issue has been Google's alleged preferencing of results from its subsidiary services above those of its competitors, constituting an abuse of dominance. ${ }^{9}$ While competition law is not premised on an idea of 'consumer confusion', the interests of consumers are instead comprised in the idea of 'consumer welfare' which is increasingly recognised as the goal of competition law. ${ }^{10}$ As will be seen below, inquiries into consumer welfare in the context of competition investigations can indirectly identify consumer confusion, and proposed remedies for anticompetitive conduct may also lead to increased clarity for consumers.

Complaints of anticompetitive behaviour have been made by Google's 'vertical' search engine competitors. Vertical search engines focus on a specific part of online content, including price-comparison sites, and sites offering legal and medical information. In addition to its 'generic' search engine, Google also runs its own vertical services such as Google Maps, Google Flight Search, and Google Shopping. Google's vertical competitors alleged that Google was using its dominant position in online generic search and advertising to give it an unfair advantage in these other markets, specifically by giving its vertical services higher and more prominent places in its generic search results, while lowering the 'Quality Score' of competitors' Sponsored Links (which are now simply referred to as 'ads').

\footnotetext{
${ }^{8}$ See: Angela Daly, 'Dominating Search: Google Before the Law' in René König and Miriam Rasch (eds), Society of the Query Reader: Reflections on Web Search (Institute of Network Cultures 2014) 86.

${ }^{9}$ Google is clearly the most prominent of the search engines in Europe and the US. It is the market leader in the overall European market for online search, based on either proportion of searches that are conducted through Google (for no cost to users) or its proportional share of advertising revenue (which is where Google gets its funds). So, while there are different methods of calculating shares of the search engine market in Europe, which are subject to various criticisms, Google seems to come out in all of them as possessing a dominant position in this market. The company's market share in Europe is around 90 per cent, which would be classified as 'near monopoly' according to the European Commission's past practice. See StatCounter, Global Stats Top 5 Desktop, Tablet \& Console Search Engines in Europe from May 2014 to April 2015 <http://gs.statcounter.com/\#search_engine-eu-monthly-201405-201504>. Google is also the market leader in online search and advertising in the US, with a market share of around 80 per cent, which although less than its market share in Europe, is still weighty enough to be considered a dominant position. See StatCounter, Global Stats Top 5 Desktop, Tablet \& Console Search Engines in the United States from May 2014 to April 2015 <http://gs.statcounter.com/\#search_engine-US-monthly-201405-201504>.

${ }^{10}$ Clifford A Jones, 'Foundations of competition policy in the EU and USA: conflict, convergence and beyond' in Hanns Ulrich (ed), The Evolution of European Competition Law: Whose Regulation, Which Competition? (Edward Elgar 2006)
} 
The alleged effect of this has been competitors' results appearing in a lower position and/or less often than results from Google's subsidiary services, in both generic results and Sponsored Links. If these allegations are true, then such practices may mean that users are more likely to click on Google's services rather than its competitors' vertical search services due to the prominent placement given to Google's own services in the search results page.

The European Commission ('the Commission') opened its investigation into Google in November 2010 for an alleged abuse of its dominant position contrary to Article 102 of the Treaty on the Functioning of the European Union (TFEU). ${ }^{11}$ To date, this case is the largest and most significant competition investigation into Google's conduct - and is still ongoing. While in 2014 it seemed that the Commission and Google had reached a settlement, progress seems to have been stymied by political pressures and at the time of writing the Commission has sent Google a formal Statement of Objections. ${ }^{12}$

The Commission's Statement of Objections follows various offers of Commitments from Google to settle the lengthy dispute, which the Commission has rejected. Google's Second Commitments proposal from 2013 (whose content was leaked on an American consumer rights group), ${ }^{13}$ and the critique of this proposal by some of Google's rivals, is of relevance to this article given Google's offer to alter the appearance of its search results page. Indeed, Google offered to label its own services when one or the other of them was displayed in the results page when a user did a generic search for particular terms. It was in the second offer of Commitments where it was proposed that the label should be '... accessible to users via a clearly visible icon. ${ }^{14}$ This icon should show that the result has been added by Google in order to ensure that users would not confuse it with generic search results and should indicate to users where they can find alternatives provided by Google's competitors. The results from Google's own services should be displayed in a separate area to Google's generic search results and Google also offered to display links to three rival services in '... a manner to

\footnotetext{
${ }^{11}$ European Commission, 'Antitrust: Commission Probes Allegations of Antitrust Violations by Google' (Press Release, IP/10/624, 30 November 2010) <http://europa.eu/rapid/press-release_IP-10-1624_en.htm>.

${ }^{12}$ European Commission, 'Antitrust: Commission Sends Statement of Objections to Google on Comparison Shopping Service; Opens Separate Formal Investigation on Android' (Press Release, IP/15/4780, 15 April 2015) <http://europa.eu/rapid/press-release_IP-15-4780_en.htm>.

13 Google, Commitments in Case COMP/C-3/39.740 Foundem and Others (21 October 2013) <http://www.consumerwatchdog.org/resources/googlesettlment102113.pdf>.

${ }^{14}$ Ibid.
} 
make users clearly aware of these alternatives'. ${ }^{15}$ These rivals' services would be selected from a pool of eligible vertical search competitors according to a complicated process set out in the document. Google included screenshots of how these results would be displayed, which included links to competitors being displayed under its own specialised search results in a separately boxed part of the screen and taking up roughly half of the space on the page that Google's specialised service results occupied.

In response to Google's offer, FairSearch (a lobby group comprising many of Google's search rivals) commissioned a survey with the aim of finding the likely impact of these proposals on United Kingdom-based internet users, in particular testing the extent to which users were likely to click on any of the three rival links, and whether they understood and recognised the different parts of Google's proposed search results page i.e., the labelling and descriptions. ${ }^{16}$ The survey found that 'only a modest number' of users would click on one of the rival links and that users were confused about the difference between Google's vertical search results and the other results. ${ }^{17}$ The conclusion was that if Google presented links to its rivals in a relatively neutral fashion, that is, in a comparable way in terms of appearance and placement on the page, then this would result in higher click through rates for the competitors' links. However, the Second Commitments offered by Google did not achieve this and so were not '... likely to command materially increased consumer attention or restore competition for [Google's] rivals.' 18

Since the case against Google in the EU is ongoing, it remains to be seen whether it will result in Google having to change its search results page, and if so in what ways, and to what extent the appearance of different kinds of search results will be 'clarified'. A significant obstacle may actually be in the fact that it is not clear that Google is breaching EU competition law even if it is favouring its subsidiary services over those of its rivals as this conduct does not fit squarely into recognised categories of anticompetitive abuses of

\footnotetext{
15 Ibid.

16 David J Franklyn and David A Hyman, Review of the Likely Effects of Google's Proposed Commitments dated October 21, 2013 ("Second Commitments") (9 December 2013) Fair Search <http://www.fairsearch.org/wp-content/uploads/2013/12/FairSearch-Hyman_Franklyn-Study.pdf>.

${ }^{17}$ Ibid 2.

${ }^{18}$ Ibid 13.
} 
dominance, ${ }^{19}$ although the examples of abuse given in Article 102 are not exhaustive. ${ }^{20}$ In any event, the Google investigation in the EU appears to have become politicised, which may be driving the case more than legal considerations: a coalition of European 'digital companies', mainly from France and Germany, succeeded in lobbying the European Commission, and some domestic politicians in these countries, to urge a reconsideration of the Commitments offered by Google. ${ }^{21}$

In the US, the Federal Trade Commission (FTC) launched an antitrust investigation into Google's activities, including search and advertising, which resulted in a settlement with Google in early 2013. In coming to its decision, the FTC found that Google had adopted design changes for its search results page primarily to improve the quality of its search product and the overall user experience, ${ }^{22}$ following precedents such as Kodak ${ }^{23}$ and $I B M .^{24}$ Although Google's vertical search competitors may have lost sales as a result of this improvement, in the FTC's eyes this was just a normal part of a fierce, competitive process, and the outcome for users was that there was more directly relevant information for their search queries. The FTC found that Google had not acted anti-competitively, and the company was not forced to label its results or otherwise change the operation or format of its search results page.

However, the FTC's technical competence in determining that these changes were actually improving the consumer experience rather than attempting to foreclose competitors has been questioned since it is not clear from the decision '... what types of expertise or methods the

\footnotetext{
${ }^{19}$ See: Pablo Ibanez Colomo, 'Exclusionary Discrimination under Article 102 TFEU' (2014) 51(1) Common Market Law Review 141.

${ }^{20}$ Case 6/72 Continental Can v Commission [1973] ECR 215, para 26; Case C-280/08 Deutsche Telekom v Commission [2010] ECR I-9555, para 173.

${ }^{21}$ Jeevan Vasagar, 'The News Baron Battling Google' (Financial Times, 9 June 2014) <http://www.ft.com/cms/s/0/beb7aeae-eb3d-11e3-bab6-00144feabdc0.html\#axzz3C77rQzcj> accessed 30 September 2015.

${ }^{22}$ Federal Trade Commission, Statement of the Federal Trade Commission Regarding Google's Search Practices In the Matter of Google Inc. FTC File Number 111-0163 (3 January 2013) <https://www.ftc.gov/system/files/documents/public_statements/295971/130103googlesearchstmtofcomm.pdf>. These design changes meant that Google displayed its own vertical search results more prominently and had the effect of pushing the organic search links further down the page.

${ }^{23}$ Berkey Photo v Eastman Kodak 603 F.2d 263 (2d Cir. 1979)

${ }^{24}$ California Computer Products v IBM 613 F.2d 727 (1979)
} 
FTC deployed to make such distinctions'. ${ }^{25}$ At the time of writing, it has been reported that the FTC has opened a fresh investigation into Google, although this time involving its Android mobile platform. ${ }^{26}$ This divergence in outcome from the EU competition investigation into Google may, aside from any political considerations, be based on the fact that precedents such as Kodak and IBM in US antitrust law do not clear equivalents in EU competition law.

Despite Google's likely dominant position and market power, no such investigation has taken place in Australia, with Google escaping any major public scrutiny from the Australian Competition and Consumer Commission ('ACCC') by way of a formal competition investigation. It is unclear why this has been the case - possibly because ACCC decided to allocate resources to the misleading and deceptive conduct investigation discussed below, possibly because the ACCC has already conducted a preliminary investigation and not found sufficient evidence of anticompetitive conduct, and possibly also because there is not a strong legal basis for claims of anticompetitive conduct in Australian competition law (misuse of market power) which is similar in form to EU competition law.

\subsection{Trade Mark Infringement Proceedings}

In addition to the abovementioned competition investigations, Google has also been subject to trade mark infringement proceedings across the globe with respect to its sale of trade marks as keywords to third parties (usually competitors of the trade mark owner) since trade mark owners have been concerned about the confusion this practice may cause consumers. Keyword advertising enables search providers and their advertisers to deliver relevant, tailored, consumer-specific ads to internet users. Advertisers using services such as AdWords therefore are able to specify each part of the three-part advertisement. The advertiser can also

\footnotetext{
${ }^{25}$ Frank Pasquale, 'Privacy, Antitrust, and Power' (2013) 20 George Mason Law Review 1009, 1022.

${ }^{26}$ David McLaughlin, 'Google Said to Be Under U.S. Antitrust Scrutiny Over Android' Bloomberg (New York, 25 September 2015) <http://www.bloomberg.com/news/articles/2015-09-25/google-said-to-be-under-u-santitrust-scrutiny-over-android-iezf41sg> accessed 30 September 2015.
} 
specify keywords that will trigger the appearance of the 'ad' when that keyword is entered as a search term in the Google search engine.

Google did not always allow its advertisers to link their ads to the trade marks of others, but in 2004 its advertising policy was amended in the US and Canada to allow advertisers to purchase their competitors' trade marks as keywords. ${ }^{27}$ This policy was subsequently applied to the United Kingdom and Ireland in 2008, and the rest of Europe in $2010 .^{28}$ In early 2013, the policy was rolled out further in countries including China, Hong Kong, and Australia, with Google announcing it '... will no longer prevent advertisers from selecting a third party's trade mark as a keyword in ads targeting these regions'. ${ }^{29}$

The change in policy resulted in a series of lawsuits instituted against Google for trade mark infringement. Trade mark infringement is premised on the assessment of consumer confusion, which flows from the alleged infringing use of a mark, where that use is consistent with the origin function of a trade mark - an assessment of confusion similar to that required in cases of misleading and deceptive conduct (which will be discussed in more detail later).

As to the cases of trade mark infringement levelled against Google in relation to its sale of trade marks as keywords, the company has escaped unscathed. This is because most of the lawsuits have been largely resolved in its favour or settled out of court, some on account of a lack of sufficient evidence of consumer confusion, which is a bedrock principle of trade mark infringement. $^{30}$ The most prominent of these actions in which Google was successful is

\footnotetext{
27 Google Advertising Policies Help, AdWords Trademark Policy Google <https://support.google.com/adwordspolicy/answer/6118?rd=1>.

${ }^{28}$ Matthew Saltmarsh, 'Google Will Sell Brand Names as Keywords in Europe', The New York Times (online), 4 August 2010 <http://www.nytimes.com/2010/08/05/technology/05google.html?_r=0>.

${ }^{29}$ Google Advertising Policies Help, above n 24.

${ }^{30}$ As to the settled cases, which have largely been in the United States see Soaring Helmet Corporation v Bill Me Inc (WD Wash, 2:2009cv00789, 6 June 2009). Similarly see Ezzo v Google Inc (MD Fla, 2:09-CV-00159, 17 March 2009) and Jurin v Google Inc (ED Cal, WL 5011007, 17 October 2012). See also Home Decor Center Inc v Google Inc (CD Cal, CV 2:12-cv-05706-GW-SH, 9 May 2013). Further see Rosetta Stone Ltd v Google Inc 676 F 3d 144 (4th Cir, 2012). Indeed it is worth noting that while Google was successful in the first instance - see Rosetta Stone Ltd v Google Inc (ED Va, 1:09-cv-00736-GBL-TCB, 3 August 2010); on appeal in Rosetta Stone Ltd v Google Inc 676 F 3d 144 (4th Cir, 2012), the Fourth Circuit reversed the District Court on several key points, including claims of direct trademark infringement, contributory infringement, and dilution before both parties settled on confidential terms.
} 
Google France SARL v Louis Vuitton Malletier SA, before the Court of Justice of the European Union (CJEU). ${ }^{31}$

This decision was the culmination of several years and brought together three separate lawsuits, and was received as a victory for Google and search engine operators in general. Here, Louis Vuitton brought proceedings against Google France, alleging it had allowed advertisers to purchase Louis Vuitton trademarks as keywords via Google's AdWords program, linking to websites selling imitation Louis Vuitton goods and to competing websites, in breach of Article 5 of the First Council Directive. The claim ultimately failed, with the ECJ deciding that search engine operators, as referencing service providers, do not infringe trade marks by selling keywords that correspond to third party trademarks. Although search engines are carrying out commercial activity in the course of trade, their activities do not constitute use, as required for the purposes of trade mark infringement.

While the ECJ concluded that Google's conduct did not constitute use sufficient to found a cause of action for trade mark infringement, this is not entirely consistent with some of the American case law on this issue, which in itself is conflicting. Of particular note is the case of Rescuecom Corp v Google Inc, where the Second District Court ruled that Google's actions constituted commercial use of a trade mark, sending the matter back to the District Court for reconsideration. $^{32}$ Although this decision represents a significant departure from Google France, the matter was never ultimately put before the District Court for final determination because in March 2010, Rescuecom discontinued its proceedings against Google. This can be compared to an earlier case in the United States, which found that WhenU, a marketing company that monitors a computer user's internet activity in order to provide pop-up ads, did not use the 1-800 CONTACT trade mark within the meaning of the Lanham Act, when it put

\footnotetext{
${ }^{31}$ Joined Cases C-236/08 - C-238/08 Google France SARL, Google Inc v Louis Vuitton Malletier SA, Google France SARL v Viaticum SA, Luteciel SARL, Google France SARL v Centre national de recherche en relations humaines (CNRRH) SARL, Pierre-Alexis Thonet, Bruno Raboin, Tiger SARL [2010] ECR I-02417. For a discussion of this case and the trade mark law implications: Case Note, 'Trademark Law - Infringement Liability - European Court of Justice Holds that Search Engines do not Infringement Trademarks - Joined Cases C-236/08, C-237/08 \& C-238/08, Google France SARL v. Louis Vuitton Malletier SA, ECJ EUR-Lex LEXIS 119 (Mar. 23, 2010)' (2010) 124 Harvard Law Review 648. See also Lassi Jyrkkiö, 'But I Still Haven’t Found What I'm Looking For' - The ECJ and the Use of Competitor's Trademark in Search Engine Keyword Advertising' (2011) 1 Helsinki Law Review 129.

${ }^{32}$ Rescuecom Corp v Google Inc, 562 F 3d 123 (2d Cir, 2009).
} 
the term in its database of keywords that trigger pop-up advertisements, although this finding reversed the earlier finding of trade mark use and award of injunctive relief. ${ }^{33}$

It is clear that internationally, the courts have evaded some of the key issues around search engines and trade mark infringement such that the law is not entirely settled. Even so, as the years pass the legality of Google's AdWords program is becoming more entrenched, as Google have been able to successfully stave off trade mark infringement lawsuits, with some commentators even declaring that Google have won the trade mark and keyword advertising battle. $^{34}$ As a consequence, trade mark owners have shifted their focus to the advertisers responsible for purchasing others' trade marks as keywords with better success, ${ }^{35}$ including in Australia. $^{36}$ Another alternative that has garnered attention are the laws regulating misleading and deceptive conduct and false advertising, laws which appear better suited to regulating new and emerging market activities such as keyword advertising.

\subsection{Misleading and Deceptive Conduct}

Google's conduct in relation to its search results pages and its AdWords facility has further been tested under the laws regulating misleading and deceptive conduct and false advertising. ${ }^{37}$ In Australia, the law in this area is enshrined in section 18 of the Australian

\footnotetext{
33 1-800 Contacts Inc $v$ WhenU.com Inc, 414F 3d 400 (2d Cir, 2005).

${ }^{34}$ Eric Goldman, More Confirmation That Google Has Won the AdWords Trademark Battles Worldwide (22 March 2013) Forbes <http://www.forbes.com/sites/ericgoldman/2013/03/22/more-confirmation-that-googlehas-won-the-adwords-trademark-battles-worldwide/>. There is some truth to this claim, although a closer examination of the legal basis for such decisions and the circumstances surrounding the search engine's success would suggest that such an assertion is somewhat of an exaggeration: see Amanda Scardamaglia, 'Keywords, Trademarks and Search Engine Liability' in René König and Miriam Rasch (eds), Society of the Query Reader: Reflections on Web Search (Institute of Network Cultures 2014) 163.

${ }^{35}$ See Interflora Inc v Marks \& Spencer Plc [2013] EWHC 1291 (Ch) (21 May 2013) [318] although this is now the subject of a retrial. See 1-800 Contacts Inc v Lens.com Inc $\left(10^{\text {th }}\right.$ Cir, No 11-4114, 11-4204, 11-4022, 16 July 2013) and Allied Interstate LLC v Kimmel \& Silverman PC (SD NY, WL 4245987, 12 August 2013) as examples of trade mark infringement lawsuits instituted by trademark proprietors against advertisers who have used third party trade marks as keywords, but which were unsuccessful, for want of sufficient evidence of confusion.

${ }^{36}$ See REA Group Ltd v Real Estate 1 Ltd [2013] FCA 559 (7 June 2013).

${ }^{37}$ In Australia see Google Inc v Australian Competition and Consumer Commission (2013) 249 CLR 435. For an international perspective see the discussion in Fox Van Allen, 'Google, Others Ignoring FTC Warnings on
} 
Consumer Law ('ACL') set out in Schedule 2 of the Competition and Consumer Act 2010 (Cth), which specifically prohibits traders from engaging in conduct that is misleading and deceptive or is likely to mislead or deceive. ${ }^{38}$ The section (and its antecedent) has been interpreted broadly, so that it can serve its function as '... a norm of commercial conduct which applies in dealings with the public at large, individuals and between traders. ${ }^{39}$ As such, section 18 has been applied to the use of misleading brand names, get-up or packaging of products ${ }^{40}$ and misleading business and company names ${ }^{41}$ as well as domain names. ${ }^{42}$ It also prohibits the use of misleading slogans, logos and devices and (more pertinently for the purpose of this article) misleading statements and representations made in advertising, whether that be traditional modes of advertising or internet advertising. ${ }^{43}$

One of the most notable examples pertaining to internet advertising came to a head in Australia when the ACCC instituted proceedings against Google and the Trading Post for breaching the antecedent to section 18, section 52 of the Trade Practices Act 1974 (Cth). The ACCC's case against Google related to its broader claim concerning several Sponsored Links. $^{44}$ The essence of the claim was that each of the disputed Sponsored Links was misleading or deceptive, or likely to mislead or deceive, because they included a headline that linked to the advertisers' webpage rather than to a webpage of the advertisers' competitor

Deceptive Search Ads' on Techlicious, Blog (14 October 2014) <http://www.techlicious.com/blog/benedelman-google-deceptive-search-ads/>.

${ }^{38}$ Section 18 of the ACL provides that '[a] person must not, in trade or commerce, engage in conduct that is misleading and deceptive or likely to mislead or deceive.' The inclusion of the word 'person' rather than 'corporation' is the only significant difference between section 18 and section 52 of the Trade Practices Act 1974 (Cth).

${ }^{39}$ Robert French, 'A Lawyer's Guide to Misleading or Deceptive Conduct' (1989) 63 Australian Law Journal 250, 268.

${ }^{40}$ For imitation of product shape and get-up see, eg, Parkdale Custom Built Furniture Pty Ltd v Puxu Pty Ltd [1982] HCA 44 (11 August 1982) and Interlego AG \& Lego Australia Pty Ltd v Croner Trading Pty Ltd [1992] FCA 624 (16 December 1992). For the imitation of a product name and get-up see Apand Pty Ltd v the Kettle Chip Co Pty Ltd [1994] FCA 1370 (30 September 1994).

${ }^{41}$ Re Taco Co of Australia Inc [1982] FCA 136 (22 July 1982).

${ }^{42}$ The Architects (Australia) Pty Ltd v Witty Consultants Pty Ltd [2002] QSC 139 (20 May 2002).

${ }^{43}$ This includes misleading statements made on social media sites such as Facebook: see Seafolly Pty Ltd $v$ Madden [2012] FCA 1346 (29 November 2012). Similarly, a company will be held responsible for misleading and deceptive third-party comments and testimonials posted on its social media pages if it knew of them and made a decision not to remove them: see Australian Competition and Consumer Commission v Allergy Pathway Pty Ltd (No 2) [2011] FCA 74 (10 February 2011). Further, see Advertising Standards Bureau Case Report, Case Number 0272/12, Advertiser: Diageo Australia Ltd (11 July 2012).

${ }^{44}$ For a detailed analysis of this case see Amanda Scardamaglia, 'Misleading and Deceptive Conduct and the Internet: Lessons and Loopholes in Google Inc v Australian Competition and Consumer Commission’ (2013) 35 European Intellectual Property Review 707. See also Megan Richardson, 'Before the High Court: Why Policy Matters: Google Inc v Australian Competition and Consumer Commission' (2012) 34 Sydney Law Review 587. 
whose trading or product name featured in the headline. For example, the first named respondent, the Trading Post, a classified advertising business, was alleged to have purchased 'Just 4x4s Magazine' among others as keywords (with Just 4x4s Magazine being a competitor of the Trading Post in providing classified advertising for four wheel drives). When a user entered the search terms 'Just 4x4s Magazine' into the Google search engine, they would be returned the search result as shown in Figure 1.

The dispute so far as it relates to Google centred on its publication of the alleged misleading and deceptive Sponsored Links, including the advertisement shown in Figure 1. Specifically, the ACCC alleged that by publishing or displaying the Sponsored Links in question, Google was liable for misleading and deceptive conduct, as the maker of those advertisements (and thus was subject to primary rather than secondary liability). The ACCC further claimed that Google had engaged in misleading and deceptive conduct by failing to distinguish sufficiently between its organic search results and Sponsored Links. 


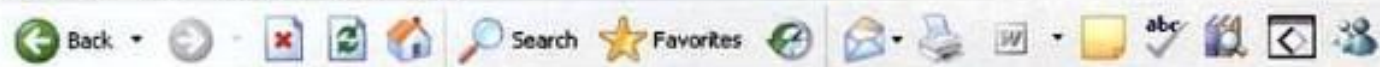

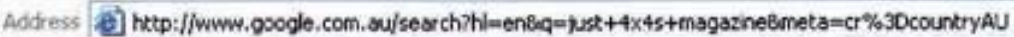

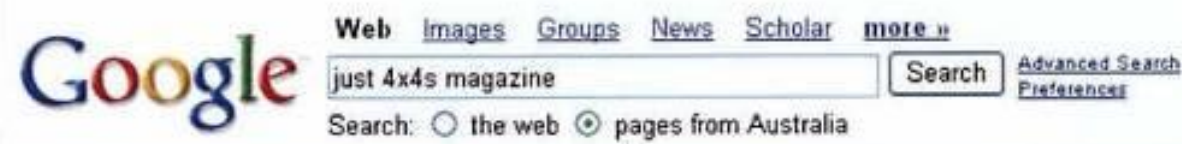

\section{Web}

Just Car Insurance

unw justcarinsurance com.

Competitive car insurance for young drivers. Check out our new web site

\section{Just $4 \times 4$ s Magazine}

umw.tradingpost.com au New \& Used 4WD Cars- See 90,000+ Auto Ads Online, Great Finds Daily

Overlander $4 W D$ : View topic- just $4 \times 4$ 's magazine

Overlander 4WD is Australia's leading off road vehicle magazine with vehicle ... Post Posted

Tue Now 08, 2005 12:40 pm Post subject: just 4 X4's magazine ...

forums overlander.com au/vewtopic. php?t=32811 - $46 \mathrm{k}$ - Cached - Simular pages

4x4 TRADER Subscriptions - Subscribe Online Here for $4 \times 4$ TRADER ...

subscriptions to $4 \times 4$ TRADER magazine now $4 \times 4$ Trader is the best way to get a great

deal ... subscriptions to $4 \times 4$ TRADER magazine from just $\$ 50.00$ per year. ...

isubscribe shopsafe com au/MagazineDirectory/4 $\times 4$ TRADER htm - $51 \mathrm{k}$

Cached-Similar pages

$4 \times 4$ TRADER

Specialising in selling everything for the recreational market, $4 \times 4$ Trader includes 4WD's,

motor-homes and caravans. The magazine focuses on informative ...

mow motorpoint com au $/ 4 \times 4$ trader_magazine asp - $111 \mathrm{k}$ - Cached-..Similar pages

[PDF] Ready Reckoner Jun 06 XLS

File Format PDF/Adobe Acrobat - View as HTML

MAGAZINE READERSHIP AND CIRCULATION 2005/06. Cover Price Frequency.

PUBLICATION ... Just 4X4's \$3.75 Monthly N/a 16185. Just Motorbikes

odsites2 itechne. com/Acp31mages/edDesk/c9572133-3a37-4929-a421.

elonom

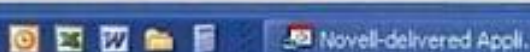

Inbox-Mcrosoft Out...

S1 $u x x$ 4xts magaane

Snonsored Links

$4 \times 4$ Magazine

Buy/Sell Your $4 \times 4$ The Fast Way

on Australia's No.1 Auto Website

WuW. carsales, com au/4x4s

New $4 \times 4$ Car Site

Search \& Compare New 4 WD Carsi

Get in Touch with Dealers Directly

Get in Touch with Dealors Oire

Are you looking for Cars?

$70000+$ New \& Used Cars in Australia

Isnt it Too Big to Miss?

unw carsguide com a

Car Magazines

Get The Most Popular Car

Magazines Up To 92\% Off The Cover!

unw MagazineCity com

Magazine Subscriptions

Get your farourite magazines

online at discount rates today

www.isubscribe.com.au

Figure 1: Google Search Engine Response to Keyword Search for JUST 4X4S MAGAZINE 
Although the proceedings against the Trading Post were settled, the case against Google was subject to protracted litigation. The matter was heard at first instance before Nicholas $\mathrm{J}$ in the Federal Court of Australia ('Federal Court'). He found that although four out of the 11 Sponsored Links subject to dispute were misleading and deceptive such that the advertisers were liable, Google itself had not made those representations. ${ }^{45}$ As to the claim that Google had failed to sufficiently distinguish between its organic search results and Sponsored Links, Nicholas $\mathbf{J}$ found that ordinary and reasonable members of the public who have access to a computer connected to the internet would have understood Sponsored Links were advertisements that were different from Google's organic search results such that Google was not liable for any misleading and deceptive conduct constituted by those advertisements.

The ACCC appealed, challenging the finding that Google had not made any false and misleading representations. The finding that Google had not differentiated between its organic search results and Sponsored Links was not subject to appeal. ${ }^{46}$ Here, the Full Court of the Federal Court unanimously reversed the decision of the judge at first instance. ${ }^{47}$ Google appealed the decision of the Full Court, and the matter went before the High Court where in a much publicised and anticipated decision, ${ }^{48}$ the bench unanimously allowed the appeal.

Significant to this finding was the fact that the evidence against Google ' $[\ldots]$ never rose so high as to prove that Google personnel, as distinct from the advertisers, had chosen the relevant keywords, or otherwise created, endorsed, or adopted the Sponsored Links. ${ }^{49}$ As such, Google was not liable as the maker of misleading and deceptive advertising content.

\footnotetext{
${ }^{45}$ Australian Competition and Consumer Commission v Trading Post Australia Pty Ltd [2011] FCA 1086 (22 September 2011).

${ }^{46}$ That the ACCC did not appeal this finding is not surprising given this was a finding of fact, and appeal judges are unlikely to disturb findings of facts as the trial judge is considered to be in the best position to make such a determination.

${ }^{47}$ Australian Competition and Consumer Commission v Google Inc [2012] FCAFC 49 (3 April 2012).

${ }^{48}$ See Richardson, above $\mathrm{n} 41$.

${ }^{49}$ Google Inc v Australian Competition and Consumer Commission (2013) 249 CLR 435, 460 [71] (French CJ, Crennan and Kiefel JJ).
} 


\subsection{The Relevant Class of Consumer in Google v ACCC}

As noted earlier, section 18 of the ACL provides that '.. a person must not, in trade or commerce, engage in conduct that is misleading or deceptive or which is likely to mislead or deceive.' The words 'misleading or deceptive' are not defined in the ACL. Indeed, the words were not defined in section 52 of the Trade Practices Act 1974 (Cth) which it replaced. There is however a long catalogue of cases which labour over the meaning of the term, providing some clarification.

The difference between misleading conduct and deceptive conduct is subtle. Conduct which is merely confusing will not be in breach of section 18. Moreover, if a defendant's conduct only causes a consumer cause to 'wonder' about a state of affairs, such conduct will not be actionable. ${ }^{50}$ A tendency to cause confusion or uncertainty is also insufficient. ${ }^{51}$ Thus, a consumer must be misled about a state of affairs for the conduct to fall under the category of misleading conduct - such that they are led into error ${ }^{52}$ or are likely to be led into error. ${ }^{53}$

The intent of the defendant is irrelevant to the extent that conduct can be misleading even where the defendant had no intention to mislead. ${ }^{54}$ Intention is however relevant to the question of determining what constitutes deceptive conduct. Lockhart $\mathrm{J}$ in Bridge Stockbrokers suggested that deceptive conduct would include conduct that was deliberately confusing. ${ }^{55}$ Conduct is likely to mislead or deceive, if there is '... a real, and not remote, chance or possibility regardless of whether it is less or more than fifty per cent. ${ }^{56}$

\footnotetext{
${ }^{50}$ Parkdale Custom Build Furniture Pty Ltd v Puxo Pty Ltd (1982) 149 CLR 191.

${ }^{51}$ Taco Co of Australia Inc v Taco Bell Pty Ltd (1982) 42 ALR 177.

${ }^{52}$ Parkdale Custom Build Furniture Pty Ltd v Puxo Pty Ltd (1982) 149 CLR 191, 198.

${ }^{53}$ S \& I Publishing Pty Ltd v Australian Surf Life Saver Pty Ltd (1998) 43 IPR 581, 588.

${ }^{54}$ Although section 4 of the ACL provides that where a corporation makes a representation as to any future matter without reasonable grounds, that misrepresentation shall be taken to be misleading.

${ }^{55}$ Bridge Stockbrokers Ltd v Bridges (1984) 4 FCR 460, 474.

${ }^{56}$ Global Sportsman Pty Ltd v Mirror Newspapers Ltd (1984) 55 ALR 25, 30.
} 
The process for determining whether there has been a breach of section 18 was set out in Taco Co of Australia Inc v Taco Bell Pty Ltd. ${ }^{57}$ Here, Deane and Fitzgerald JJ spoke of identifying the relevant section of the public, considering who falls within that section and inquiring as to why the proven misconception has arisen. ${ }^{58}$

Pursuant to this test, it is clear that central to any claim of misleading and deceptive conduct is the class of relevant consumer - that being the standard against which the alleged infringing conduct must be measured. Where the persons allegedly misled or deceived are not identified individuals but are members of a class, it is necessary to isolate 'a representative member' of the class and determine whether this hypothetical individual is likely to have been misled or deceived. When considering the likely effect of the conduct on this hypothetical person he or she should be judged as an 'ordinary' or 'reasonable' member of the class. The consequence is that 'extreme' or 'fanciful' reactions to the conduct are to be disregarded. Thus, in determining whether conduct has been misleading or deceptive:

It seems clear enough that consideration must be given to the class of consumers likely to be affected by the conduct. Although it is true, as has often been said, that ordinarily a class of consumers may include the inexperienced as well as the experienced, and the gullible as well as the astute, the section must, in my opinion, be regarded as contemplating the effect of the conduct on reasonable members of the class. The heavy burdens which the section creates cannot have been intended to be imposed for the benefit of persons who fail to take reasonable care of their own interests. What is reasonable will of course depend on all the circumstances ... 59

Accordingly, the hypothetical consumer will be expected to take reasonable care, and will not be overly gullible or astute, or experienced or inexperienced. But what about the reasonable Internet user? With respect to the section 18 claim levelled against Google in ACCC $v$ Trading Post, Nicholas $\mathrm{J}$ at first instance defined the relevant class of consumers as:

... people who have access to a computer connected to the internet. They will also have some basic knowledge and understanding of computers, the web and search engines including the

\footnotetext{
${ }^{57}$ Taco Co of Australia Inc v Taco Bell Pty Ltd (1982) 42 ALR 177, 202 (Deane and Fitzgerald JJ).

${ }^{58}$ Taco Co of Australia Inc v Taco Bell Pty Ltd (1982) 42 ALR 177, 203 (Deane and Fitzgerald JJ).

${ }^{59}$ Parkdale Custom Build Furniture Pty Ltd v Puxo Pty Ltd (1982) 149 CLR 191, 199 (Gibbs J).
} 
Google search engine. They will not necessarily have a detailed familiarity with the Google search engine but they should be taken to have at least some elementary understanding of how it works. It is not possible to use a search engine in any meaningful way without knowing something about how it operates. ${ }^{60}$

\section{Nicholas J went on to say:}

The ACCC submitted that there was a relevant class of consumers consisting of first time users of the Google search engine who were unlikely to understand the difference between Sponsored Links and organic search results. There was no evidence to show what proportion of people using the Google search engine are likely to be first time users. I am not willing to infer in the absence of evidence that the numbers of first time users are likely to be significant. But, in any event, while a person using a search engine (including the Google search engine) for the first time might be confused by the initial experience, this response is likely to be very short lived. Any confusion arising out of first use is of a temporary and commercially irrelevant kind that may be disregarded for the purpose of determining whether there has been any misleading or deceptive conduct or whether there is a real risk of it occurring in the future: SAP Australia Pty Ltdv Sapient Australia Pty Ltd (2000) 48 IPR 593 at [51]. ${ }^{61}$

The class of consumers identified by Nicholas $\mathrm{J}$ was defined on the basis of several inferences about internet users - inferences that were undisturbed as the matter progressed to the High Court. One such inference was that it is not possible for consumers to use a search engine without knowing how it operates. There is of course a great irony in this assumption as Google is so secretive about the operation of its search engine and its algorithm. Indeed, its whole business model plays precisely on the fact that people do not know exactly how it operates. Nicholas $\mathrm{J}$ also assumed that people understand the difference between organic and paid-for search results, believing that Google does not endorse the content it delivers - it simply transmits the messages of others, as some kind of 'neutral' conduit.

\footnotetext{
${ }^{60}$ Australian Competition and Consumer Commission v Trading Post Australia Pty Ltd [2011] FCA 1086 (22 September 2011) [122] (Nicholas J).

${ }_{61}$ Australian Competition and Consumer Commission v Trading Post Australia Pty Ltd [2011] FCA 1086 (22 September 2011) [168] (Nicholas J).
} 
Google itself has claimed that it operates its search and advertising business with a 'handsoff' neutrality and that results are generated in a 'technical' or 'mechanical' way. However, the methods Google uses to determine results are designed in particular ways which involve the value judgements of humans regarding how to collect and present the data. ${ }^{62}$ Indeed, Google's management of its search and advertising business has been conceptualised as being analogous to making editorial judgements about information akin to a newspaper. This is significant particularly in the US context - Google may be considered a 'speaker' for First Amendment purposes with the implication that the government is not able to regulate what is presented by Google in its search results nor the way in which it is presented. ${ }^{63}$ This may also have been a consideration in the FTC's antitrust decision discussed above. Thus, the extent to which Google's management of its services is considered a mechanic and distant activity, or entails a more involved and active role for Google, has an important impact on Google's legal rights and responsibilities.

This article does not seek to answer the question of what level of 'active' involvement Google has in determining search and advertising results. Instead, the following parts of this article seek to answer another question: namely the extent, if any, to which Australian consumers are in fact misled or deceived by Google's search results page, and in doing so, provide an evidence-based foundation for the 'relevant consumer' in any future Australian internet cases, as well as providing a comparison for similar inquiries in other jurisdictions. In doing so, it is acknowledged that the question of whether conduct is misleading or deceptive is a question of fact that should be determined objectively by the court in Australia, rather than by strict reference to empirical evidence as to the actual reaction of potential or actual consumers. ${ }^{64}$ This is also the case for other common law jurisdictions where such evidence is usually presented by one party or other during the adversarial process. The following findings are therefore not intended to provide an empirically-based answer to the question posed in the Google Inc v ACCC litigation or to suggest that had this evidence been

\footnotetext{
${ }^{62}$ Eric Goldman, 'Search Engine Bias and the Demise of Search Engine Utopianism' (2006) Yale Journal of Law and Technology 111, 113; Marina Lao, 'Neutral' Search as a Basis for Antitrust Action?' (Harvard Journal of Law and Technology Occasional Paper Series 2013) 3

${ }_{63}$ Eugene Volokh and Donald M Falk, 'First Amendment Protection for Search Engine Search Results', (Google White Paper, 2012) <http://www.volokh.com/wpcontent/uploads/2012/05/SearchEngineFirstAmendment.pdf> accessed 30 September 2015.

${ }^{64}$ See, eg, McWilliam's Wines Pty Ltd v McDonald's System of Australia Pty Ltd (1980) 33 ALR 394, 399 where Smithers J suggested there was scant authority supporting the view that empirical evidence measuring the public reaction was of any relevance.
} 
presented in court by the ACCC, the results may have been different. Instead, the purpose of this data is to provide an evidence-based account of the 'reasonable internet consumer' or user - to provide a better foundation for evidence-based policy and judicial decision-making on internet advertising in Australia and beyond and the operation of Google more generally. In the process, this data may therefore provide cause for reflection on the Google Inc v ACCC case.

\section{Empirical Research}

In Australia, prior to this research being conducted, there was no empirical evidence in existence on whether internet users, as consumers, understand the difference between the different parts of the Google search results page. Internationally, such evidence does exist, but it is conflicting as to whether consumers are actually confused or do actually understand the nature and operation of Sponsored Links and results from Google's subsidiary services. ${ }^{65}$ For example in Rosetta Stone Ltd v Google Inc, the US Court of Appeals for the Fourth Circuit cited an internal Google study finding that even sophisticated consumers were sometimes unaware that Sponsored Links were advertisements. ${ }^{66}$ This can be compared to Franklyn and Hyman's findings in a study on the use of trade marks as keyword in advertising, the result of a natural experiment which found that there was little evidence of traditional actionable consumer confusion regarding the source of goods from a trade mark law perspective. ${ }^{67}$ However, at the same time, that study also found that only a minority of consumers correctly and consistently distinguished paid ads from unpaid search results.

\footnotetext{
${ }^{65}$ For example in Rosetta Stone Ltd v Google Inc, 676 F 3d 144 (4th Cir, 2012), the US Court of Appeals for the Fourth Circuit cited an internal Google study finding that even sophisticated consumers were sometimes unaware that Sponsored Links were advertisements. Compare this to the findings set out in David J Franklyn and David A Hyman, 'Trademarks as Search Engine Keywords: Much Ado About Something?' (2013) 26 Harvard Journal of Law and Technology 481. Franklyn has been a recipient of a grant from the Microsoft Corporation to conduct empirical research on internet search results labelling and paid ad placement.

${ }^{66} \mathrm{See}$, eg, the aforementioned Google study referred to above in Rosetta Stone Ltd v Google Inc, $676 \mathrm{~F} 3 \mathrm{~d} 144$ (4th Cir, 2012). See also Benjamin Edelman and Duncan S Gilchrist, Advertising Disclosures: Measuring Labeling Alternatives in Internet Search Engines (13 January 2012) $<$ http://www.benedelman.org/adlabeling/adlabeling.pdf>. Edelman is a consultant for Google's competitor, Microsoft.

${ }^{67}$ Franklyn and Hyman, above n 62.
} 
Earlier studies on Google search indicate higher levels of confusion, although such findings may not be surprising, as at that time it may be argued that users were not yet accustomed to the operation of search and were not familiar with its distinguishing features. For example, in 2003 a Consumer Web Watch study found that consumers, all with a minimum of five years' of online experience, did not understand how search engines prioritise results or how the inclusion of paid search listings might influence the types of web pages they see first. ${ }^{68}$ Similarly, a 2005 study conducted by the Pew Internet \& American Life Project found that while $38 \%$ of internet users were aware of a distinction between paid and unpaid results, $62 \%$ were not. ${ }^{69}$

There are obvious limits to the existing data. As well as being inconclusive and contradictory, some of the data is out of date and does not reflect the current operation of Google search. Moreover, much of the available evidence has been commissioned by partial actors, including Google itself as well as Google's competitors. As such, little to no independent and unaligned research into this issue has been undertaken, and certainly none so far emanating from Australia. The authors are wholly independent of Google and its competitors/opponents: we received no money from these sources for this research, but were instead funded by internal grants from our university. This study and the research findings presented in this article therefore are the first of their kind in relation to Australian internet users, and represent unaligned independent research which may also be useful for the purposes of international comparison.

The survey also extends beyond questions relating to the distinction between paid and organic search results and considers the broader question of consumers' general understanding of Google search results, given the Google results page is now far more complex since the facts of the Google v ACCC case. Before delving any further into the

\footnotetext{
${ }^{68}$ Leslie Marable, False Oracle: Consumer Reaction to Learning the Truth About How Search Engines Work, Results of an Ethnographic Study (30 June 2003) Consumers Union <http://consumersunion.org/wpcontent/uploads/2013/05/false-oracles.pdf>.

${ }^{69}$ Deborah Fallows, Search Engine Users - Internet Searchers are Confident, Satisfied and Trusting - But They are also Unaware and Nä̈ve (23 January 2005) <http://www.pewinternet.org/files/oldmedia/Files/Reports/2005/PIP_Searchengine_users.pdf.pdf>.
} 
methodology of this survey, a brief summary of how Google works and the different elements of Google search is now provided.

\subsection{How Does Google Work?}

When a user enters a term in the Google search engine, they are given two main search results: organic (or natural) search results and Sponsored Links. Much has already been written elsewhere about the technical process involved in producing organic or unpaid search results. $^{70}$ Suffice to say that at the most basic level and for present purposes, organic search results provide links to web pages that are ranked in order of 'relevance' to the search terms entered, as determined by a complex algorithm developed by Google. ${ }^{71}$ Although the precise nature and workings of the algorithm remain unknown, the use of the Google algorithm means that organic search result rankings cannot be purchased from Google. ${ }^{72}$

Ads, or Sponsored Links as they were previously known, are a form of advertising created by advertisers which pay the relevant search provider each time a user clicks on the link - hence the term 'pay per click' advertising. Ads are the lifeblood of Google, generating almost US $\$ 60$ billion in revenue for the company in $20144^{73}$ Google displays ads separately from

\footnotetext{
${ }^{70}$ See in particular Eric Goldman, 'Deregulating Relevancy in Internet Trademark Law' (2005) 54 Emory Law Journal 507, 511-28.

${ }^{71}$ It is known that some of the factors used to determine the 'relevance' of a page include: the type of content, the quality of content, how recent the content is, the user's region, and how many other sites link to that one and how important those linking sites are in terms of traffic and prominence: see Google, Inside Search: How Search Works: From Algorithms to Answers $<$ http://www.google.com/intl/en_us/insidesearch/howsearchworks/thestory/>. Google also uses information such as the use of secure, encrypted connections (HTTPS) as a signal in its search ranking algorithms: Google, HTTPS as a Ranking Signal (6 August 2014) Google Online Security Blog <http://googleonlinesecurity.blogspot.com.au/2014/08/https-as-ranking-signal_6.html>.

${ }^{72}$ Instead, advertisers use search engine optimisation services to manipulate the visibility of their webpage in a search engine's natural or unpaid organic search results. This is important since all of the research indicates that consumers do not go further than the first page of Google's search results. The research further indicates that users are more likely to click on organic search results rather than Sponsored Links. Indeed, Google's own research indicates that $66 \%$ of ad clicks occur when there is no associated organic search result on the first page: Google, New Research: Organic Search Results and their Impact on Search Ads (27 March 2010) Google Inside AdWords <http://adwords.blogspot.com.au/2012/03/new-research-organic-search-results-and.html>.

${ }^{73}$ This represented $17 \%$ year on year growth: see Google, 2014 Financial Tables Google Investor Relations < https://investor.google.com/financial/2014/tables.html>.
} 
organic search results. Historically, these ads appeared in a shaded box marked 'Ad' or 'Ad/s related to...' and were positioned to the left of organic search results. Over time, the page layout was redesigned and ads also started to appear above organic search results. The labelling of ads has also changed over time, and currently, they are labelled with a more discrete 'Ad' icon which may or may not appear in a shaded box.

The order and ranking of ads, and whether they will appear at all in response to a user query, is not determined by the standard Google algorithm. Instead, their ordering is determined by Google's AdWords program. AdWords allows advertisers to create, change and monitor the performance of ads. These ads consist of three parts. The first part is the headline, which incorporates a link to a webpage. The second part is the webpage's address. The third part of the link is the advertising text, which usually consists of a brief summary of the subject of the ad and sometimes the advertiser's business.

In the early days, Google's search results page was essentially a combination of organic search results and ads, and this provided for a relatively clean page with each of the two main elements delineated by labels and shading. As Google has grown and its services evolved, Google's search results page has become increasingly complex, with several competing elements. Many of these search results elements are derived from Google's subsidiary 'vertical search' services which provide users with a specific category of online content, such as Google Maps, Google News and Google Shopping. The search results page can also include what Google refers to as 'Refinements,' incorporating features like advanced search, related searches, and other search tools, which are designed to help users fine-tune their search query. ${ }^{74}$

Another addition to Google's search results page is the Knowledge Graph. According to Google, '[t]he Knowledge Graph enables you to search for things, people or places that Google knows about - landmarks, celebrities, cities, sports teams, buildings, geographical features, movies, celestial objects, works of art and more - and instantly get information

\footnotetext{
${ }^{74}$ Google, Inside Search above n 68.
} 
that's relevant to your query. ${ }^{, 75}$ The relevant information Google refers to appears on the right hand side of the search results page linking to public sources, including Wikipedia. ${ }^{76}$ The information shown in this section is derived from a collection of information about real world things and their connections to other things, where the Knowledge Graph gathers information about a topic from several sources, before refining the information based on the most popular questions people ask about that subject.

Furthermore, the precise composition of the Google search page layout will differ for each user, depending on their region, their preferences and settings, their own browsing history and of course the devices they use - whether a PC, laptop, tablet or mobile phone. The focus of this study and the discussion in this article is on the search results pages displayed for PC users only. $^{77}$

\subsection{The Survey}

The data which forms the basis of this article was collated from an online survey of a demographically-representative sample of 1014 Australian adults during November $2014 .^{78}$ The questionnaire was drafted by the authors and an external market research company (Research Now) was engaged to enlist the representative panel of respondents and to programme and coordinate the delivery of the survey and produce the survey data in raw

\footnotetext{
${ }^{75}$ Google, 'Introducing the Knowledge Graph: Things not Strings' on Google, Google Official Blog, (16 May 2012) <http://googleblog.blogspot.com.au/2012/05/introducing-knowledge-graph-things-not.html>.

${ }^{76}$ While links to Wikipedia appear prominently, the precise relationship between Google and Wikipedia is unclear.

${ }^{77}$ For more about the precise scope of this article, see the discussion on limitations at part 3.3.

78 The panel was selected using the most recent Australian Bureau of Statistics data to ensure it was representative of the Australian adult population on account of gender, age, location, education, occupation, income country of birth and language spoken. As to panel quality and selection see Research Now, Panel Quality: Our Values - Answers to Esomar's 28 Questions <http://www.researchnow.com/enUS/Panels/PanelQuality.aspx>. An online panel was considered to be the most suitable for this research project for the following reasons: (1) Other modes of survey have low response rate (such as mail survey) and high cost (e.g., face to face survey); (2) An online panel is more representative of the population where $80 \%$ of the population have access to the internet. The chance of sampling error or non-response error are minimised in an online survey as compared to the traditional survey methods; (3) An online survey provides adequate time for the respondents to reflect on their answers when there are large numbers of variables that need to be measured on the survey instrument (as of this research).
} 
form. The authors engaged a research assistant skilled in data gathering and analysis to aid in interpreting the raw data obtained from Research Now. The survey was drafted in light of the parameters of some existing, analogous surveys from the US and Europe, ${ }^{79}$ with the following research question in mind: to what extent, if any, are Australian consumers misled and/or deceived when using the Google search engine? The only qualifying question for participation in the survey was: 'Do you use Google Search?' The survey was designed in accordance with the parameters of the Australian law on misleading and deceptive conduct, but the concept of consumer confusion transcends this area of Australian law and so this survey and its results may be informative for other areas of law and other jurisdictions.

Prior to the collection of data, the survey instrument was pre-tested with a convenience sample of 30 people. The results from the soft launch were used to revise the survey instrument into its final form. The final questionnaire comprised nine demographic questions (to ensure a representative panel was selected) and 26 substantive questions. As already noted, the substantive questions were framed with the purpose of obtaining data about consumers' understanding of Google search results and the provenance and purpose of different kinds of results. All questions were posed as multiple choice questions, save for two questions which were open text. The first sequenced open text question asked how Google could improve the layout and labelling of results. The second sequenced open ended question was the survey's final question which asked respondents for their closing remarks. Thematic analysis was used to code these responses according to prominently displayed themes.

The respondents were asked some background questions about which devices and browsers they used and what respondents did when they were online (work, study, shopping etc). The remainder of the questionnaire was structured around two screenshots of Google search results pages from the Chrome browser on a desktop PC. ${ }^{80}$ The Chrome browser was selected as it is the most popular browser used in Australia. ${ }^{81}$ The screenshots related to the search

\footnotetext{
${ }^{79}$ See Franklyn and Hyman, above n 62. See also Stefan Bechtold and Catherine Tucker, 'Trademarks, Triggers, and Online Search' (2014) 11 Journal of Empirical Legal Studies 718.

${ }^{80}$ The Chrome browser was downloaded specifically for the purpose of conducting this research and so there was no browsing history, save for the two searches conducted for this survey.

${ }^{81}$ This was also confirmed by the data collected in this survey, with $36.6 \%$ of respondents using the Chrome browser, followed by Internet Explorer (30.5\%). As the survey only deals with search results produced using one browser, the data is limited, a point discussed further in section 3.3 of this article.
} 
terms 'apple' and 'rolex' (see a copy of the screenshots below in Figure 2 and Figure 3), which are both brand names and registered trade marks, although of course 'apple' has a generic meaning as well. Each key element of the search results page was framed in a black box and labelled (Section A-G and Section A-K) post facto and presented to respondents. The breakdown of each section for each screenshot is shown in Table 1 and Table 2.

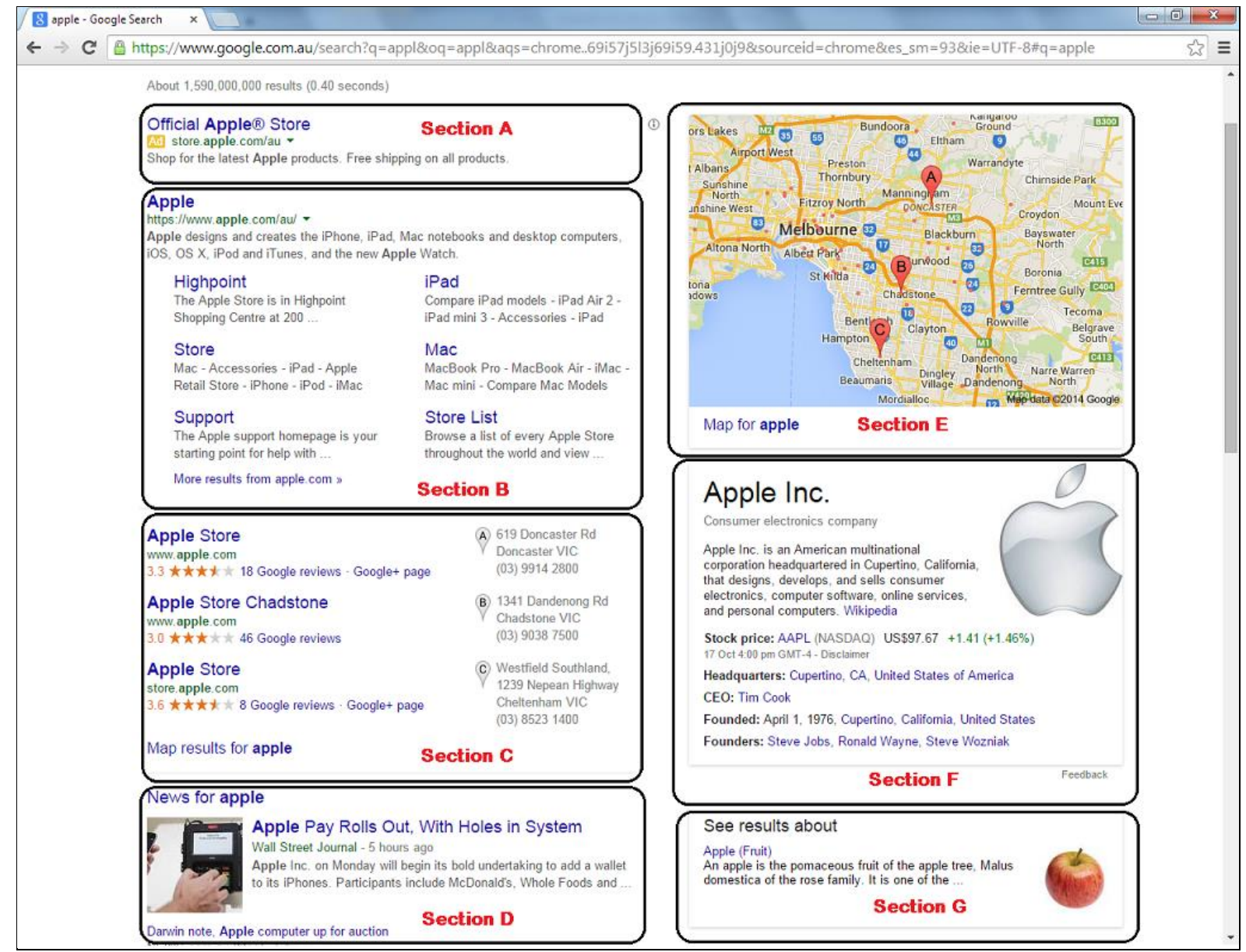

Figure 2: Google Search Screenshot: 'apple' 
Table 1: Breakdown of Google Search Screenshot: 'apple'

\begin{tabular}{|l|l|}
\hline Section & Description \\
\hline Section A & Sponsored Links \\
\hline Section B & Organic or natural search results \\
\hline Section C & Google maps \\
\hline Section D & Google news results \\
\hline Section E & Google maps \\
\hline Section F & Knowledge graph box \\
\hline Section G & Results about box \\
\hline
\end{tabular}

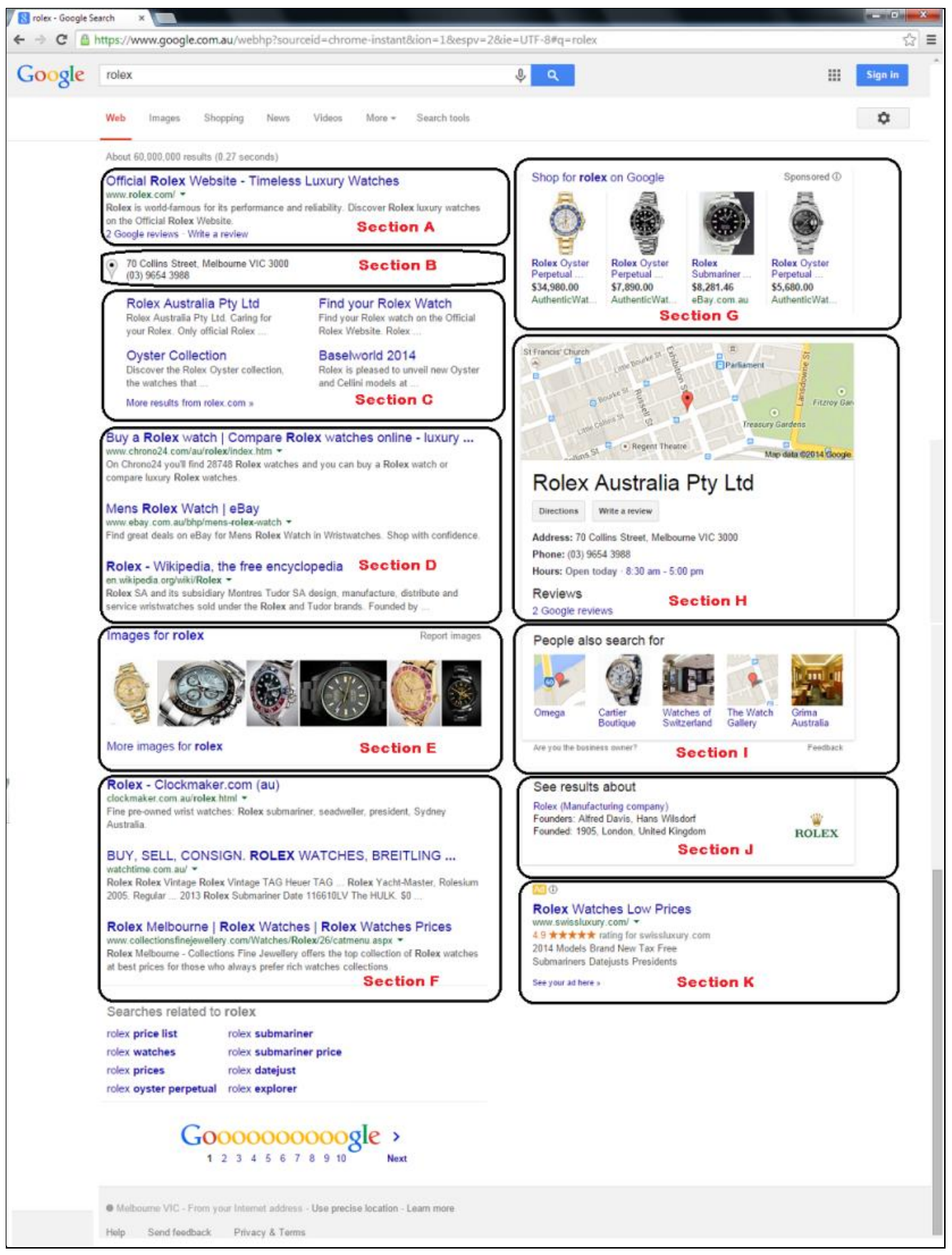

Figure 3: Google Search Screenshot: 'rolex' 
Table 2: Breakdown of Google Search Screenshot: 'rolex'

\begin{tabular}{|l|l|}
\hline Section & Description \\
\hline Section A & Organic or natural search results \\
\hline Section B & Google maps \\
\hline Section C & Organic or natural search results \\
\hline Section D & Organic or natural search results \\
\hline Section E & Google images \\
\hline Section F & Organic or natural search results \\
\hline Section G & Google shopping results \\
\hline Section H & Google maps \\
\hline Section I & People also search for \\
\hline Section J & Results about box \\
\hline Section K & Paid advertisements/Sponsored Links for ads \\
\hline
\end{tabular}

\subsection{Survey Limitations}

As previously stated, the search results pages shown in Figures 2 and 3 were generated using a PC. Different results may be yielded for different devices, and thus this is a limitation of this study. The findings are still pertinent, however, as PCs are widely used, and the survey showed that respondents' primary device was a laptop (32.1\%) followed closely by a PC (29.7\%). Mobiles phones (7.8\%) and tablet devices (7.8\%) were equally popular. Further research into the search results generated on laptops and mobile devices would be worthy of consideration in a future study.

Another limitation relates to the way in which the Google search results pages were presented to respondents. As noted, the search results pages as generated in response to a search for the terms 'apple' and 'rolex' were modified to the extent that each section or component of the search results page was framed, boxed and labelled. This may have had the effect of delineating the different elements of the Google search results page in a way that respondents would have otherwise not been able to delineate themselves. As a consequence, the data may be somewhat distorted, such that the incidence of confusion in the survey results was actually under-reported. 
The data was also limited to the extent that the survey questions related to two search queries for 'apple' and 'rolex'. While Apple Inc sells popular and well-known consumer goods, Rolex is a high-end luxury brand. As such, different responses may have been yielded from a search term that was less affordable as opposed to a brand that is more frequently purchased.

The final limitation relates to the formulation and sequencing of questions, which may have primed some of the responses later in the survey. That is, and to quote Franklyn and Hyman who acknowledged a similar limitation in their own survey: '... particular questions may be affected by survey respondents' interpretation of the goals of the survey. So, survey respondents might conclude that there is something problematic about [the search results pages] from the simple fact that we constructed a survey devoted to the issue. ${ }^{, 82}$

\subsection{Results}

Now that Google's operation, the survey design and limitations have been outlined, the results of the survey are presented below. Overall, respondents exhibited a lack of understanding about the operation and origin of the different parts of the Google search results page. They are best able to understand and identify ads, as compared to their understanding and identification of organic results and results from Google's subsidiary services. There was particular confusion in relation to the operation and origin of Google's Shopping service.

\section{Google Search Screenshot: 'apple'}

Having been shown the 'apple' screenshot, respondents were initially asked which of the highlighted sections they would likely click on, assuming they were interested in buying a

\footnotetext{
${ }^{82}$ Franklyn and Hyman, above n 62, 528
} 
new Apple Inc smartphone. Most respondents (43.6\%) said they would click on the organic search results, while $30.6 \%$ of respondents said they would click on the ad.

Most respondents believed that Apple Inc had paid to appear somewhere on the search results page $(62.9 \%)$; although $30.2 \%$ were unsure whether this was the case. When probed further about the various sections of the 'apple' search results page and the displayed screenshot, it was clear that the respondents did not have a clear understanding of which sections of the search results page were being displayed because they were 'relevant' and which sections contained results which were 'paid for' by Apple Inc. Respondents also did not demonstrate a clear understanding of the origin or provenance of different kinds of search results. Indeed, many respondents wrongly believed that Apple Inc had paid to appear in the sections displayed, when this was not in fact true.

For the ad in the 'apple' search results page, $58.7 \%$ of respondents correctly believed that Section A (advertising) appeared because Apple Inc had paid for its placement. However, when respondents were shown Section B (an organic search result), 36.4\% believed this appeared because Apple Inc had paid for its placement and only $49 \%$ thought that this section appeared because of its 'relevance'. The perception that the search results page was a product of 'paid placement' was evident with respect to the other sections displayed and the respondents' responses. For example, when shown Sections C and E (Google Maps), 33.3\% and $26.4 \%$ of respondents respectively believed these sections were displayed because Apple Inc had paid Google to appear there. Only $13.8 \%$ and $21.6 \%$ of respondents were able to correctly identify the fact that the Google Maps results in Sections C and E respectively were from an affiliated Google service.

Twenty-two per cent of respondents also wrongly believed that Apple Inc paid to appear in the Google News results shown in Section D, with only $19.8 \%$ of respondents able to correctly identify the fact that Google News is an affiliated Google service. Respondents were even more confused about the origin of the Knowledge Box (Section F) as 35\% of respondents believed this was a paid-for placement. Respondents were less confused when it came to the 'Results About' (Section G) box as only $15.8 \%$ of respondents thought this had 
been paid for. Almost 55\% of respondents believed that Section G appeared based on relevance. Only $9.6 \%$ of respondents thought this was another Google service.

When respondents were later asked some more general questions about the 'apple' search results page, $62.1 \%$ of respondents were aware Section A was a paid-for ad (confirming the results of the earlier question) and $68 \%$ of respondents knew Apple Inc and any of its competitors could pay for the ad placement. This is perhaps not surprising, as ads are a longstanding feature of Google search, and so users are familiar with them and have become accustomed to seeing them and their positioning in the Google search results page.

At the same time, the data shows that $67.4 \%$ of respondents were unaware that organic search results could not be purchased by advertisers and thus were different from Sponsored Links. Even less (47.9\%) knew that organic search results were determined by Google's algorithm.

When asked about the origin and provenance of some of the other search results features, particularly those that emanate from Google and are part of Google's vertical search services, respondents' understanding of how these worked was mixed. So when shown Sections C, E and D, $58.9 \%$ of respondents said they knew that Google sometimes displayed links to its affiliated services - but, importantly, $72.9 \%$ did not think Google made it clear which search results emanated from its subsidiary services. Respondents were also confused about results such as the Google Knowledge Box (Section F) and the Results About links (Section G) with $51.7 \%$ of people not aware of the fact that Google sometimes generated these links and that they were different from organic search results and Sponsored Links - instead providing them with quick previews of information and facts relating to their search query.

\section{Google Search Screenshot: 'rolex'}

Next, survey respondents were shown the 'rolex' screenshot. The 'rolex' screenshot differed from the 'apple' screenshot in that it also produced a link to Google Shopping (Section G). 
Respondents were initially shown Section G and the Google Shopping section of the search results page and asked if they were aware that this link related to Google Shopping, an affiliated Google service. Nearly $70 \%(68.2 \%)$ of respondents were unaware that this was a result from one of Google's affiliated services. Even so, $42.5 \%$ of people stated that they would click on Section $\mathrm{G}$ for the purpose of buying a Rolex watch.

\section{Google Labelling etc}

Respondents were next asked about Google's labelling and whether they believed the different parts of Google's search results page were adequately and appropriately labelled. Overall, an average of $59.6 \%$ of people either agreed or strongly agreed that Google clearly labelled and differentiated each section of the search results page. The fact that each section had been boxed and labelled for the purposes of the survey (as noted earlier) may have had an impact on this result, such that respondents under-reported confusion.

Critically and in contradiction to the above results, $68 \%$ of respondents agreed or strongly agreed that Google could improve the layout and labelling of results to make their origins clearer to users. When asked how Google might do this in an open ended question, a thematic analysis revealed some common themes and suggestions, including:

- Better differentiation of sections (e.g. borders, colour-coded sections, separation) (21.4\%)

- Better, clearer labels (14.8\%)

- Better headings $(7.7 \%)$

- Reduce options and 'clutter' from search results page (4.9\%)

Some respondents asked for more 'transparency' and 'honesty' in the search results $(15.7 \%)$ while $14.7 \%$ of people wanted ads distinguished from unpaid results. These themes were also apparent in the open ended responses provided in the final survey question, where participants were asked for their closing remarks about Google and the operation of its search engine. One respondent said: I possibly trust them too much ... [Respondent identifier \# 
252]. Others noted that the survey had opened their eyes to the way Google search actually functions:

- thanks, but $i$ had noidea (sic) how google worked, now i have some idea, thank you. [Respondent identifier \# 853]

- This survey has made me more aware of how google is displaying result to a search and how they are pushinng (sic) advertising. [Respondent identifier \# 1115]

- I never knew it was so complicated. No wonder I often get lost in unwanted information. [Respondent identifier \# 1134]

\subsection{Analysis}

Several important points emerge from analysing the data collected.

Firstly, a majority of these Australian Google users do seem to understand and be able to identify paid advertisements included in the search results page. At least, their understanding and identification of these results is better than their understanding of organic search results and ability to their identify results from Google's affiliated services. Yet, even though a majority of users could correctly identify paid-for ads and understood their provenance, the remaining $30 \%$ or so who misunderstood and misidentified paid-for ads may demonstrate sufficient confusion to be actionable at law. ${ }^{83}$

When it comes to organic search results, Australian consumers' understanding is more mixed. While most respondents correctly understood that these particular results were not paid-for, the $36.4 \%$ who erroneously believed these results were paid-for may also constitute sufficient confusion to be actionable at law. Moreover, respondents' general understanding of organic search results was not high, with $67 \%$ unaware that they could not be purchased by

\footnotetext{
${ }^{83}$ When specifically asked whether they were aware that Section A of the 'apple' screenshot was a paid-for ad, $37.9 \%$ of respondents answered No.
} 
advertisers, and only a minority being able to correctly identify that these results were determined by Google's search algorithm. Thus, even if respondents were mostly able to identify organic search results on the page, their lack of knowledge of how these results are generated and the fact they cannot be purchased from Google demonstrates a more profound level of confusion.

Finally, as regards subsidiary Google services, respondents' understanding was even more limited, despite a majority being aware that Google sometimes displayed links to these subsidiary services. Very few respondents were able to identify Google Maps, Google News and Google Shopping as being subsidiary Google services. A significant minority erroneously believed that Apple Inc had paid to appear in the Google Maps and Google News results. Indeed, a majority of respondents did not think Google made it clear which search results emanated from its subsidiary services. The fact that respondents were unable to identify these results correctly and were not aware how they were generated suggests that they displayed the greatest level of confusion in relation to Google's subsidiary services.

Thus, while this survey is a preliminary investigation into Australians' understanding of the operation of Google's search engine and the results it produces, the findings do suggest that Australian consumers may experience confusion when using Google search Although it is highly unlikely that a preliminary survey such as this would be admissible in court proceedings, the survey results suggest that the assumptions made about Australian internet users and their use of Google's search engine in the course of the Google v ACCC litigation as described earlier in this article are incorrect, or at the very least, should be questioned.

In particular, the inference made by Nicholas $\mathbf{J}$ that it is not possible for consumers to use a search engine without knowing how it operates is not borne out by the survey results. Indeed, our results show that even though they use Google's search engine, many Australian consumers do not understand some of Google search's basic features, including the existence of some of Google's vertical services. As to Nicholas J's other assumption - that people understand the difference between organic results and Sponsored Links or ads- the results of this survey also significantly contradict and undermine this statement. 
As such, it is possible that had the ACCC produced empirical survey evidence of Australian consumers' understanding of Google's operation and search results, there may have been a different result in the Google v ACCC litigation. In any event, while it may be contended that the survey results presented in this article do show a measure of confusion among Australian internet users regarding the operation of Google's search engine and the results it produces, as mentioned above, this evidence is insufficient in itself to establish liability for misleading and deceptive conduct in Australia. Yet, the results suggest that this is a topic on which further and more thorough research into Australian consumers' understanding of Google's search results would be highly desirable.

In the meantime, there are some tangible measures Google could take to pre-empt any legal challenges for engaging in misleading and deceptive conduct. As the results of this survey indicate, consumers desire that Google improve the layout and labelling of its results. Google's Second Commitments proposal in the context of the EU competition investigation, as referred to earlier, may be instructive in this regard. Here Google proposed to adjust its labelling so that its vertical search services would be accompanied by a clearly visible icon. The confusion in relation to the distinction between organic search results and ads as demonstrated by this survey would suggest that such visible and obvious icons should also be extended to these elements of the search results page.

\section{Conclusion}

The survey evidence presented in this article points to some level of confusion among Australian consumers in relation to the different elements of Google's search results pages, and their provenance. In particular, it indicates that consumer confusion is highest in relation to the provenance of Google's vertical search services and its newer search features or 'refinements.' At the same time, there still remains substantial consumer confusion about the origin of paid-for ads and organic search results - confusion that might be actionable in law. 
Less of a concern is the use of trade marks and third party trade marks in advertising, as the survey indicated that consumers are familiar with Google's Sponsored Links or ads, their position on the search results page and their nature and origin.

There are several implications that may emanate from these findings.

First, given the evidence of confusion produced in this article, and in light of the outcome of the trade mark and competition cases from various jurisdictions as discussed earlier, it is submitted that the strongest remaining prospect of a successful legal challenge against Google with respect to the layout of its search results page in these jurisdictions would be by consumers (or their representatives) and possibly also trade mark owners for misleading and deceptive conduct, the decision in Google $v$ ACCC notwithstanding. This is also notwithstanding the ongoing EU competition investigation into Google, but for the reasons given above the legal basis of this investigation in terms of past EU competition law and enforcement practice can be questioned, and Google may also be able to appeal an adverse finding to the EU's General Court on this ground. Accordingly, an action in misleading and deceptive conduct would appear to have the more robust legal basis, assuming there is also appropriate evidence.

This conclusion also accords with some recent comments from the US regarding similar prohibitions on misleading and deceptive conduct in that jurisdiction as being the area of law now most likely to present a successful challenge to Google's business practices as regards its search results pages. ${ }^{84}$ Indeed, at the time of writing, Google is apparently under scrutiny by the FTC for not sufficiently labelling advertisements. ${ }^{85}$

The other implication of this research pertains to what this might mean for Google search in the future. In the Australian context, more empirical enquiry into this issue would be

\footnotetext{
${ }^{84}$ Van Allen, above $n 34$

${ }^{85}$ Matt Southern, 'Google Faces Criticism from FTC for "Deceptive” Search Ads', Search Engine Journal (15 October 2014) <http://www.searchenginejournal.com/google-faces-criticism-ftc-deceptive-search-ads/118188/>
} 
welcome, including further and more detailed research into Australian consumers' understanding of Google's search engine and the results it produces. The survey evidence detailed in this article may still prove to be persuasive and instructive in the sense that Google may consider taking steps to label the different parts of its search results pages more clearly, in order to avoid future investigation and litigation on these points, and to deliver a better search experience to consumers. This survey evidence may also better inform policy makers and government agencies such as the ACCC, which in seeking to promote the interests of consumers, can draw on these findings to implore best practice from Google. 